\title{
0809 GOOD EYESIGHT A BASIC PRECONDITION FOR SAFETY AND PERFORMANCE IN SPORTS
}

G Jendrusch*, B Lingelbach, D Schulz, P Platen Correspondence: Department of Sports Medicine and Sports Nutrition, Ruhr-University Bochum, Germany, Overbergstr. 19, D-44780, Germany

10.1136/ip.2010.029215.809

Vision delivers the basis for orientation, for example, when entering a training ground. Vision has a crucial importance for movement control and balance regulation and helps anticipating, for example, fast movements in ball games as well as potential accident risks, for example, in one-on-one-situations in football. We generated a visual performance profile for sports (including visual acuity, refraction error, dynamic vision, contrast sensitivity and depth perception). 1.500 vision tests with athletes of German national teams or first division have been carried out. In summary, visual acuity deficiencies were identified with more than $20 \%$ of the elite athletes, which the players were not previously aware of but which are to be classified as requiring correction. $25 \%$ of the athletes tested used a vision aid in daily life, for example, when driving a car. $30 \%$ of those with visual correction for nearsightedness did not use a visual aid during physical activity. On one hand, there was a lack of awareness about the effect visual performance has on sporting performance; on the other hand the correction used was unsuitable to go in for sports. Further studies show that with a reduction in vision the ability to recognise potential accident risks and the quality of depth perception or eye-hand-coordination decreases rapidly. So, with a view to injury prevention, it is important to wear a visual aid during sports if necessary! Visual function tests should be included in health diagnostics to detect and subsequently correct visual deficiencies in time. 